\title{
ePerícia: Web and Mobile Computing Environment for Public Forensic Data Management and Collect
}

\author{
Thiago M. B. Rodrigues \\ Computer Science, Federal \\ University of Tocantins \\ 109 Norte, Av. NS 15, 77001-090, \\ Palmas, Tocantins, Brazil
}

\author{
Glenda M. Botelho \\ Computer Science, Federal \\ University of Tocantins \\ 109 Norte, Av. NS 15, 77001-090, \\ Palmas, Tocantins, Brazil
}

\author{
Ary H. M. Oliveira \\ Computer Science, Federal \\ University of Tocantins \\ 109 Norte, Av. NS 15, 77001-090, \\ Palmas, Tocantins, Brazil
}

\begin{abstract}
Crime in Brazilian society has always been the object of reflection and cause for concern. Based on scientific principles, criminal expertise is one of the first filters in the criminal investigation process. Improvements in the processes of detection, identification, collection, storage and analysis of traces lead to better results in crime prevention and resolution. Thereby, specialized software becomes an indispensable work tool. The ePerícia is a software toolkit that aims to assist in the standard activities of Forensic Analyst and to support decision-making by public security agencies. For crime scene activities, an application developed for mobile platforms enables the registration of a vast amount of related information, replacing the traditional printed forms, as well as location marking, descriptive photographic record, sketches elaboration and events classification. It enables the data management and production of reports descriptive and quantitative and criminal spots to support public security policies development.
\end{abstract}

\section{General Terms}

Information System, Mobile Computing, Software Engineering, Criminal Investigation, Applied Computing.

\section{Keywords}

ePerícia, Criminal Scene Investigation, Applied Management System, Criminal Scene Investigation, Information System.

\section{INTRODUCTION}

The Official Forensic Departments of Criminal Nature are indispensable units that guarantee answers to the society in relation to their rights and allow the discovery of authors of criminal activities. In Brazil, criminal expertise plays an essential role in society, because it performs investigative work by conducting forensic examinations to obtain technical and scientific information about the qualification of an act, fact or activity. Thus, it is necessary to find out from the authors to the reasons and circumstances in which a crime was executed. In this process, the forensic analyst performs data collection, provides information, elaborates the discussion and concludes the examinations by providing a final opinion in an award [1]. The tests provide essential inputs for conducting the criminal process seeking all forms of evidence of the "real truth".

In this context, information technology has a fundamental role, mainly due to the development of forensic techniques that have increased instruments and mechanisms of potential use, which contributes substantially to the elucidation and fight against crime and impunity. However, in many Brazilian states, as well as in Tocantins, there is still a great lack of information systems for criminal management. This problem limits the work of forensic analyst who, in general, do not have access to the technological means to perform their function in the most efficient and effective way. Given this reality, this paper proposes a software product set, called ePerícia, which integrated, support the main forensic activities in the scope of the Tocantins State.

The construction of ePerícia was carried out jointly with the Forensic Analyst in the city of Palmas-TO. In this process, difficulties were observed in relation to the information and data preservation that, consequently, limit the later retrieval and analysis of the data whenever necessary. During construction it was observed that the forensic analyst still used the printed forms, resulting in a great accumulation of papers and difficulties in the production of forensic reports. The Forensic Report is the materialization of the forensic examination. It is a written piece where the Analyst Forensic objectively describes his studies, observations and research about the performed analyses. This is a very important document that is used as a base piece in criminal proceedings by the Judiciary, Public Ministry, prosecution assistant, offended, plaintiff and accused [15].

In view of the presented context, this paper presents the development and implementation of ePerícia, whose objective is to meet the demands related to the activities developed by the Forensic Analyst, regarding the storage, analysis, consolidation and dissemination of forensic data. The project contemplates the development of a software products set to assist the standard activities of Forensic Analyst and to support decision-making by the intelligence agencies of the Public Security Secretary. ePerícia confers a greater degree of accuracy, availability and publicity of forensic data, in addition, it bases actions and safety public policies more efficient and just.

The ePerícia project was awarded by the Laboratory of Participation and Innovation for Homicide Reduction, coordinated by the Public Security National Secretary of the Justice Ministry in partnership with the Executive Secretary of the Justice Ministry through public edicts 01 and $02 / 2015$ [16]. The competition aimed to promote technologies with the potential to be adopted jointly with public security actions in order to enhance the results of the public security policy. The project was selected by a judging committee composed of representatives of the following national institutions: (i) Public Security National Secretary; (ii) Executive Secretary of the Justice Ministry; (iii) Youth National Secretary of the General Secretary of the Republic Presidency; (iv) Human Rights Secretary of the Republic Presidency; (v) Secretary of Policies for the Promotion of Racial Equality of the Republic Presidency; (vi) Secretary of Policies for Women of the 
Republic Presidency; (vii) Brazilian Forum of Public Security and (viii) SINESP's Management Council.

\section{THEORETICAL FOUNDATION}

The development of this work required a bibliographical survey on the institutions responsible for the criminal investigation activities in Brazil, as well as the functions performed by the forensic analyst in the execution of their professional activities. The Official Forensic Analysis of Criminal Nature in Brazil is defined as an activity of responsibility of the State, approved in Brazilian law and determined by the Code of Criminal Procedure (CPP). The article 158 of Decree-Law no. 3.689 of October 3, 1941 [8] states that the carrying out of a forensic analysis is necessary: "When the infraction leaves traces, it will be indispensable the corpus delict exam, direct or indirect, and it cannot be supplied by the confession of the accused" [8].

Article 92 of the Constitution of the Federative Republic of Brazil of 1988 [7], defines the agency that integrate the Brazilian Criminal Justice System and article 144 lists the various agency that compose the Brazilian public security, in all its spheres, expressly defining the attributions and each agency (Brazil Constitution, 1988/2001). The Forensic Analysis is part of this system through the Criminalistics National Institute of the Federal Police, at the federal level; and by the Criminalistics Institutes and Medical-Legal Institutes, within the scope of the States and Federal District. In addition, law no. 12.030, of September 17, 2009, is responsible for the legality of the Official Forensic Analysis of Criminal Nature in Brazil [14], which clearly shows the need for autonomy to carry out the works of nature forensic.

\subsection{Forensic Activity in the Crime Scene}

Crime is all typical and culpable conduct practiced by a human being [20], which constitutes offense (harm or danger) to an individual or collective legal good. The crime scene is any physical scene anywhere, that can provide potential evidence for the investigative work of a forensic analyst, and may include a person's body, vehicles or objects. Thus, a place where a homicide, suicide, accident, fire, explosion, qualified robbery, trampling, vehicle collision, etc., has been designated as a crime scene or place of fact, because it becomes necessary to elucidate the circumstances in which the same occurred [20].

The crime scene is any area where a fact occurs that takes the form of a criminal offense and therefore requires police action [12]. The forensic analyst in the crime scene has as initial responsibility the recognition and collection of material evidence. He goes on to analyze and evaluate the results obtained in the laboratory and to present his findings to judges, members of the Public Minister, lawyers and people who need information [13]. After the analysis of the documentation of the place where the crime occurred and the evidence, it is prepared the planning to carry out the local examination, considering the characteristics of the environment to be investigated and its geographic location, when the time needed to carry out of the fieldwork, as well as the materials and equipment to be used.

During the site examinations of the local, the Forensic Analysts, with the help of the other team members, carry out measurements, do geo-referencing of the local, photograph and elaborate sketches of the local (performing a drawing of the crime scene where each record is positioned for that the relations of distances and position can be better analyzed). This stage of the work is carried out with the aid of several equipments, such as: wheel track, laser track, GPS (Global Position System), among others [20]. The examination of the crime scene is a process aimed at recording the scene as it was first encountered and the recognition and collection of all material evidence potentially relevant to the solution of the case [13]. Therefore, it is the responsibility of forensic analyst in crime scene to preserve, recover, identify, process and collect all evidence related to the crime.

\subsection{Preservation of the crime scene and evidences}

The most important aspect of collecting and preserving evidence is to protect the crime scene. This is done with the aim of keeping the relevant elements safe from contamination until they can be recorded and collected. The successful prosecution of a case may depend on the state of the physical evidence at the time it is collected. According to the Code of Criminal Procedure, Decree-Law n ${ }^{\circ} .3 .689$ of October 3, 1941 [8], which in articles $6^{\circ}$ and $169^{\circ}$ describe the functions of the authorities at the crime scene, as soon as they are aware of the practice of the criminal offense. Scene protection begins with the arrival of the first police officer at the crime scene and ends when the scene is released from police custody. All forensic analysts and police departments must have intensive training on how to protect properly crime scenes. When they arrive at the place, it is necessary to make notes about the state of the crime scene upon arrival and after the place has been stabilized. In addition, it is necessary to make notes regarding the time of arrival and departure, special attention should also be given to the floor in the room on the arrival of the forensic analysts, since this is the most common repository for evidence and represents the greatest potential for contamination of the local.

Some things the officer must observe at the crime scene include: the condition of doors, windows and lighting (natural and artificial); if there are any odors present; if there are any signs of activity that may have altered the scene; and anything important related to the victim. The entry of unauthorized persons at the crime scene must be prohibited. Investigators and other persons required (police, fire department and etc) should be contacted and sent to the location, however, under no circumstances, the scene phone should be used. Once the officer is in crime scene, he must record names of witnesses and other persons who may have entered or were at the crime scene; must separate suspects and witnesses; should not discuss events or crime with witnesses or spectators or let witnesses discuss these events; among other things. From the beginning to the end of the forensic analysis of the crime scene, it is important to apply strict measures to avoid contamination. They include: wearing protective clothing (gloves and shoe covers); employ a single path when entering in the local (this also applies to medical personnel in the care of the victim); avoid the use of any resources available on the local (bathroom, water, towels, telephone); not eating, drinking or smoking; to avoid moving something or anyone, unless it is absolutely necessary. If something or someone is moved, the initial location must be carefully documented [20].

\section{METHODOLOGY}

The ePerícia allows the forensic data collect of an occurrence at the crime scene from a mobile application. Data are sent to the database server and made available for access by a web application. The communication between the mobile application, called the client, and the web application is intermediated by a middleware layer, responsible for access 
control and data exchange. Fig. 1 presents the ePerícia architecture with its three main modules:

- Client: supports the forensic activities carried out at the crime scene via a mobile application for the collection and storage of forensic data.

- Middleware: receives the data collected at the crime scene and stores it in the central database as soon as the mobile device has an internet connection.

- Server: allows registrations, changes and/or exclusions of forensic data in the web system that concentrates all collected data.

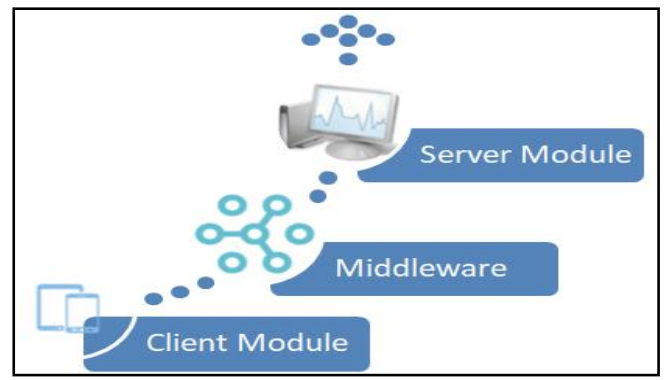

Fig 1: Architecture of the ePerícia system

\subsection{Privacy and Use Terms of ePerícia}

They are privacy and use terms for the correct execution and management of the system:

- The e-Perícia product suite allows forensic analyst registered and authenticated to insert data collected locally into a database.

- The registration for use of ePerícia is carried out exclusively by the access control entity of the Public Security Secretary.

- It is forbidden to make more than one registration per user, as well as, use the registration of another user.

- Access control entities of the Public Security Secretary may, without prior notice, block and cancel access to ePerícia when they find that the User has practiced any act or conduct that: (a) violates laws and regulations; (b) contrary to the rules of the Use Terms and; (c) violate the morality and good manners principles.

- All and any actions performed or content published by the User during the use of the application will be at his sole and entire responsibility.

- Public Security Secretary reserve the right to include, exclude or change the contents and functionality of the software, as well as suspend them temporarily or cancel them at any time, regardless of prior notice to Users. In the same way, it can modify these Use Terms, whose latest version will always be available for consultation in the own software.

- The User is exclusively responsible for all and any content that he or she sends or publishes.

\subsection{Method}

To collect data for ePerícia construction, a methodology of requirements engineering was applied in three stages: elicitation, requirements analysis and evaluation and validation as shown in Fig. 2. In the elicitation stage were adopted techniques of interviews, document analysis, user stories, brainstorm and ethnography. These techniques were selected based on the scenario and artifacts provided by the forensic analysts. The elicitation techniques are the methods adopted to allow the understanding of the client's needs, whether users or not. The objective of elicitation techniques is to discover the greatest number of requirements so that the technical team can build the best product according to customer requirements $[11,6,10]$.

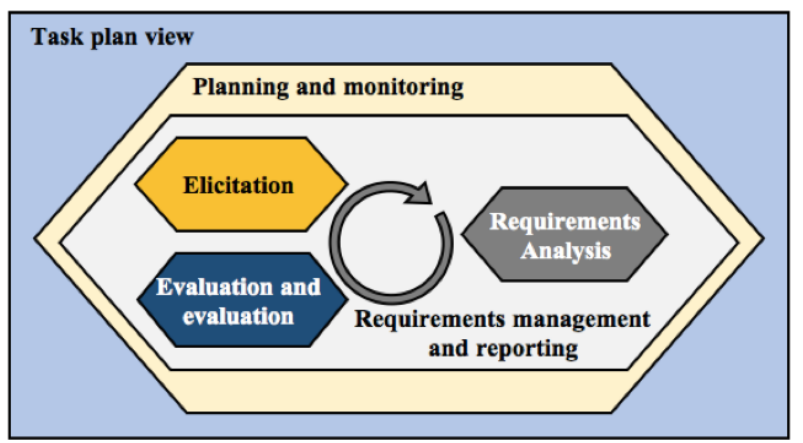

Fig 2: Activities performed in the requirements elicitation

The interview is a systematic approach to obtain information from a person or people group by asking relevant questions and documenting the responses [19]. This method allowed deep discussions on the thoughts of the forensic analyst and others involved to get their perspectives on the need for the system and the feasibility of the solution potential. The documents analysis involved the collection and revision of the documents used and produced by the forensic analyst to allow the identification of relevant information to predict system characteristics and functionalities [19]. The analysis was based on reports, printed forms models used in the performing forensic tests, among others.

Through user stories, forensic analyst has described what they expected from features in the software under their perspectives. The method allowed the description of the modernization expectations provided by an information system and the needs that it could supply. With this method, it was stimulated the functionalities description that would generate value in the work execution in the Criminalistics Institute. With the brainstorm adoption, all forensic analyst and developers gathered in groups to give their opinion about the expected functions. Everyone was free to idealize the intended functions and gave immediate feedback to the development team's proposals.

The ethnography was carried out by observing the workplace of the experts to analyze the automation needs of daily activities. Ethnography allowed to obtain the system and organizational requirements that were omitted by the techniques. Accompaniments and observations of the experts' work were carried out for several weeks at the Forensics Institute of the Palmas city. The method allowed the annotation and construction of schemes describing how the activities are carried out in the corporation.

In the requirements analysis stage, requirements organization and verification activities were performed through use cases and prototypes. In the evaluation and validation stage, the prioritization of the requirements was used to identify the most important characteristics to be built in the project. This step helped to define which were the most important functionalities and, consequently, which modules of ePerícia would need to be constructed as a priority. Typically, when a requirement is evaluated and marked as a priority, its implementation is fixed for the development iteration that is 
starting. If a requirement is not prioritized, it enters the queue to be implemented in the future. The non-prioritized requirement is implemented in a next iteration. The requirements that are in the queue are evaluated and if still valid, they are included in the candidate requirements list along with the new ones that have been identified. If a requirement is not important enough, it remains fixed on the waiting list.

\subsection{Development process of ePerícia}

The ePerícia construction was carried out adopting the agile development methodology of Scrum systems. The choice of method was due to its organizational characteristics in development iterations (sprints), new versions available at the end of each iteration (pieces of software are delivered quickly for use), as well as the follow-up and interaction of client in the development process. With this, it was possible to identify new user stories, through use cases, and the need to change the project more conveniently and with the least time possible, avoiding major changes that would impact in the development schedule and, consequently, costs.

ePerícia was built by adopting the agile development process Scrum (https://www.scrum.org/), adding several techniques to guide the system construction in an organized way, fast (efficient) and meeting the needs of the customer (effective). Scrum consists of 03 generic steps (planning, execution and conclusion) executed in short development cycles that respond well to possible adaptations for inclusion, exclusion and change of requirements during the project. The Scrum methodology was adapted for this project through a set of activities distributed in 04 general steps. Fig. 3 provides an overview of the Scrum steps execution.

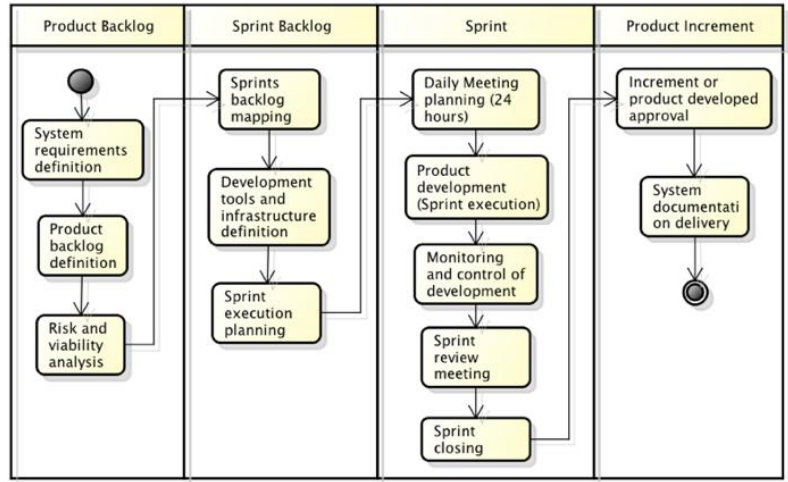

Fig 3: Scrum steps adopted in ePerícia development

The first step called Product Backlog consists of building a list with requirements and their priorities. Requirements define the functionality to be delivered to the customer. Priorities determine the risk and development order. More risks are treated as a priority. The second step named Sprint Backlog is composed by a list of items selected of the Product Backlog that will be developed during the next Sprint. This list is agreed during the Sprint Planning Meeting, that is the moment when the development team decides what will be done on Sprint.

Sprints are effectively composed of system development activities (analysis, design, construction and testing). It is characterized by short duration (between 7 and 30 days). A 15 minutes meeting is held daily to identify what has been done at Sprint, what is the schedule for the day, and whether there is a problem preventing development progress. Development monitoring and control mechanisms are applied in order to maintain the schedule within the stipulated period. Review meetings are held, used to review completed and unfinished works, and to provide a demonstration of what has been developed for the client. There is also a Sprint finish activity, which includes the retrospective of the Sprint to review mistakes and correctness. At the end, the Sprint is closed.

Product Increment is the last step. It's an increase of a delivery within a given period. Increments are software pieces that attend to a set of functional requirements.

\subsection{Software Testing}

The testing activity is designed to investigate, evaluate and verify the integrity and quality of the software. It is a process of running a system with the intention of finding errors. The test seeks to ensure the product conformity in relation to regulatory, business, technical, functional and user requirements. The tests in ePerícia were carried out according to the characteristics identified in the elicitation, considering users' needs and the availability of resources. Unit, performance, integration and usability tests were performed, according to Fig. 4. Tests will be detailed in the following sections.

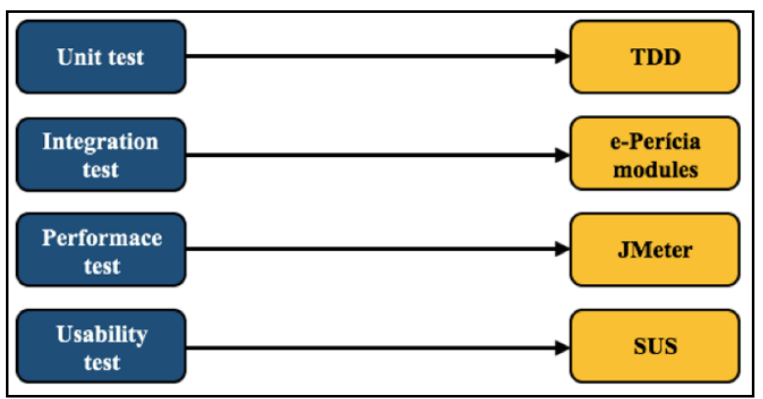

Fig 4: Tests applied in the development of ePerícia system

\subsubsection{Usability Test: System Usability Scale}

This test was used to measure the effectiveness of the ePerícia system in the usability aspect. It was decided to apply the System Usability Scale (SUS) for a subjective analysis of usability by users. The SUS consists of a questionnaire that is reliable and easy to apply [4, 17, 5]. It consists of 10 questions, which the user responds on a scale of 1 to 5 where 1 means fully disagrees and 5 fully agrees. After collecting the results of the questionnaire application, the result is calculated to obtain the final score. To do this, it is necessary to subtract 1 from the user's answered scores in the odd questions (1, 3, 5, 7 and 9), and for even answers (2, 4, 6, 8 and 10), subtract 5 of the response. That is, if the user replied 2 , count 3 , but if the user answered 4, count 1 . The SUS has a scale of 5 levels (from F to A), omitting the letter E. The letter $\mathrm{F}$ represents the worst level of usability and letter $\mathrm{A}$ the best. The 5 levels are divided as follows:

- Below 60 points: F score, system poor in usability.

- Above 60 and below 70 points: D score, considered a reasonable system, however, with a need for investments in usability.

- Above 70 and below 80 points: C score, the system is considered good, that is, it does not present serious usability problems.

- Between 80 and 90 points: the system falls into one of the highest usability categories, receiving a $\mathrm{B}$ score. The system is excellent.

- Above 90 points: The system falls within the category of usability maximum excellence, thus receiving A score. 


\subsubsection{Test-driven development}

Test-driven development (TDD) has become popular among developers because it is one of the most important practices in any agile development method [3]. In TDD, a developer considers the test cases and scenarios firsthand. The test cases check for several bug cases and scenarios that the developer was not aware, making the source code less prone to errors and creating a solid foundation for future versions of the software. This technique suggests that a unit test be developed before implementing the production code $[2,9,18]$.

In practice, a developer introduces a new crash test, then writes the smallest code piece in the production code so that the test suite runs successfully. At the end, if necessary, the code is reformatted to provide a better framework for the solution in production. Test-driven development gives a broader view of what needs to be done, because before creating the functionality, you should create a test to check and validate the new function.

\subsubsection{Performance Tests}

Every information system has implicit performance requirements. A software should not have an infinite time or resource for its execution. Performance errors generally refer to design problems that cause system performance degradation. Performance evaluation of a system typically includes resource use, throughput, stimulus-response time, and detailing the average or maximum number of tasks that are expected to be served by the selected resources. Common resources that need to be considered include network bandwidth requirements, CPU cycles, disk space, disk access operations and memory usage [20]. Therefore, the purpose of this test is to identify performance impairment, compare and evaluate performance.

The JMeter tool was used to execute the performance test. JMeter is an open source program in Java designed for load testing and performance measurement. It can be used to simulate multiple scenarios in different ways. JMeter exports test results in different formats, including CSV and XML files and graphics.

\subsection{Tools}

The ePerícia server module was developed in the Python language with the Django framework. The client module was designed with the Apache Cordova framework, which allows the use of standard web technologies such as HTML5, CSS3 and JavaScript for multiplatform development. For this project, we opted for a set of simple and efficient tools allowing a productive development with quality.

- Postgre SQL: database system developed as an open source project (http://www.postgresql.org/). It has sophisticated features such as multi-version concurrency control, recovery point, replication, among others.

- AngularJS: javaScript framework that extends HTML attributes through directives and links that data to HTML through expressions (https://angularjs.org/).

- Virtualenv: tool for creating isolated virtual environments for Python projects (https://virtualenv.pypa.io/en/latest/). It enables the creation of a virtual environment in a directory for the installation of the necessary packages for the environment. The tool allows the creation of a virtual environment for multiple projects on the same machine.

- Nginx: fast and lightweight web server with various forms of configuration to improve performance. Free server that integrates easily with various tools and supports activities of automatic load balancing (https://www.nginx.com/).

- Pip: installation management of package and software libraries written in the Python that make the installation more convenient (https://pip.pypa.io/en/stable/).

\section{RESULTS AND DISCUSSION}

The results will be discussed in the presentation format of the most relevant functional and non-functional requirements, showing the main iteration screens of ePerícia and the results of the usability, unit, integration and performance tests. The system was deployed in the Criminalistics Institute in the Palmas-TO city in March 2017 and until this point 70 screens were generated, linking the web and mobile versions.

\subsection{Functional (FR) and Non-Functional Requirements (NR)}

Functional requirements describe the key functionalities automated by ePerícia. Tables 1, 2, 3 and 4 presents the main functional and non-functional requirements. Forensic automation for crimes of traffic, against property and against life has been foreseen. The most relevant functional and nonfunctional requirements were listed.

\section{Table 1. Functional Requirements of General} Registrations Module

\begin{tabular}{|c|}
\hline Module: General Registrations \\
\hline $\begin{array}{c}\text { RF0001: Forensic analysis management: registration, } \\
\text { update and exclusion of forensic analysis. Includes queries } \\
\text { by date and number of forensic analysis. }\end{array}$ \\
$\begin{array}{c}\text { RF0002: Register general information of forensic analysis } \\
\text { in crime scene: it stores date, time, action form and } \\
\text { authority requesting the forensic analysis. }\end{array}$ \\
$\begin{array}{c}\text { RF0003: Record information about the suitability of the } \\
\text { crime scene: it stores information about isolation and } \\
\text { preservation of the crime scene, occurrence classification } \\
\text { and which police authorities were present. The location of } \\
\text { the forensic analysis is georeferenced by means of latitude, } \\
\text { longitude and altitude coordinates. }\end{array}$ \\
\hline $\begin{array}{c}\text { RF0004: Manage images of forensic analysis: involves } \\
\text { inclusion and exclusion actions of images from the crime } \\
\text { scene. }\end{array}$ \\
\hline $\begin{array}{c}\text { RF0005: Manage forensic analysis annotations: text editing } \\
\text { to annotate observations undertaken at a crime scene. }\end{array}$ \\
\hline $\begin{array}{c}\text { RF0006: Sketch completion: allows to fill in the sketches } \\
\text { related to the three crimes types foreseen in the system. The } \\
\text { sketches of traffic crimes and crimes against life will be } \\
\text { presented in the results section. }\end{array}$ \\
\hline
\end{tabular}

Table 2. Functional Requirements of Traffic Crimes Module

\begin{tabular}{|c|}
\hline Module: Traffic Crimes \\
\hline $\begin{array}{c}\text { RF0007: Include traffic crime information: records } \\
\text { information about location, type, victims, vehicles, } \\
\text { witnesses, traces and other information. }\end{array}$ \\
\hline $\begin{array}{c}\text { RF0008: Information management about traffic crime } \\
\text { location: records information on weather conditions, } \\
\text { brightness, local topography, visibility, paving, } \\
\text { conservation and road description. }\end{array}$ \\
\hline
\end{tabular}


RF0009: Signaling information management: record information about the signaling in the local.

RF0010: Collision type management: record key types of collisions observed at traffic crime locations.

RF0011: Information management about victims: records information about the position that the victim was found, injuries, sex, name, birth, documentation, contact, address and physical characteristics (age, height, skin color, eyes color, hair color, particularities, details of the lower/upper limbs), dressing and other information.

RF0012: Manage witness information: records information about the full name, birth date, gender, personal documents, contact phone number and the report. This requirement also applies to crimes against property and against life.

RF0013: Manage vehicle information: records data of brand, model, manufacture year, color, plate, fuel, kind/type, category, occupancy capacity, chassis, mileage and driver data (driver's license, address, CPF, category).

Others information are also recorded as the vehicle conditions, the headlights tests, brakes, flashlights, steering, windshield wiper and tires. It also has complementary information, such as missing or damaged equipment, objects found inside the vehicle, impact region, breakdowns and tachograph data. This requirement is applied to crimes against property and against life when there is the involvement of vehicles.

RF0014: Manage information of traffic accident trace: records information about the traces observed at the traffic crime local, including: the traces type (crumbling, overturning, skidding, braking, rubbing, spotting and furrowing), position, length and description.

RF0015: Manage supplementary information: it records additional data of the occurrence, especially those reported by third parties (name, personal documents and location).

\section{Table 3. Functional Requirements of Crimes Against Life}

\begin{tabular}{|c|}
\hline Module: Crimes Against Life \\
\hline $\begin{array}{l}\text { RF0016: Include information of the crime against life local: } \\
\text { records details involving weather conditions, brightness, } \\
\text { building type, internal organization and attributes of traces } \\
\text { found in the immediate, immediate, and related location. }\end{array}$ \\
\hline $\begin{array}{l}\text { RF0017: Manage information about the immediate location } \\
\text { of crime against life: collect attributes of traces found at the } \\
\text { immediate location: traces type, description, state and } \\
\text { morphological aspect of spots (if any). }\end{array}$ \\
\hline $\begin{array}{l}\text { RF0018: Manage information on the location of crime } \\
\text { against life: collect attributes of traces found in the } \\
\text { location: type of vestige, description, state and } \\
\text { morphological aspect of spots (if any). }\end{array}$ \\
\hline $\begin{array}{l}\text { RF0019: Manage information about related location of } \\
\text { crime against life: collects attributes of traces found at the } \\
\text { crime scene: traces type, description, state and } \\
\text { morphological appearance of spots (if any). }\end{array}$ \\
\hline $\begin{array}{l}\text { RF0020: Managing trace information: records traces types } \\
\text { found at the crime scene: letters or documents, feces, } \\
\text { plantar/palmar imprints, seminal fluid, blood spots, } \\
\text { obstacles breakage, fighting traces, vomiting, etc. }\end{array}$ \\
\hline
\end{tabular}

RF0021: Manage information about victims of crime against life: allows to register one or more victims. The system records information about gender, name, birth, documentation, contact, address and physical characteristics (age, height, physical complementation, skin color, eye color, hair color, hair size, hair type, particularities with due details, social condition, position that was found and state of the body). The system also collects data on chronotanatognosis, general injuries type, data on injuries by firearm, hanging, electro-pressure (jellinek marks, metalization, carbonization, burning and tetanization), heat injuries (erythemas), drowning (injuries by aquatic fauna, macerated skin, face cyanosis, foam mushroom, anserine skin, etc.) and defense lesions. Lastly, data on the victim's clothing, arrangement of clothing, clothing types (top/bottom bath, shirt/shirt with long/short sleeves and prints, shorts/pants/skirts and shoes with numbering) are recorded.

RF0022: Manage information about perpetrators of crimes against life: allows to register one or more authors. The system records information on gender, name, birth, documentation, contact, address and physical characteristics (age, height, skin color, physical complementation, eye color, hair color, hair size, hair type, particularities with author details). The data on the social condition, the crime motivation, observations on the motivation and other information are also recorded.

RF0023: Manage information about modus operandi: records information about how the crime was executed. Some data are collected as the possible cause of death (accidental, drowning, natural causes, suicide, homicide, robbery), means used (firearm, white weapon, poisoning, hanging, choking, precipitation, strangulation) instruments found at the crime scene and additional information.

\section{Table 4. ePerícia Non-Functional Requirements}

\begin{tabular}{|c|}
\hline Non-Functional Requirements \\
\hline $\begin{array}{c}\text { RN0001: System Architecture: The system must operate } \\
\text { under a client-server architecture of two layers, allowing } \\
\text { clients to communicate via web browsers and mobile } \\
\text { application. }\end{array}$ \\
\hline $\begin{array}{c}\text { RN0002: Encrypted file system: The database system must } \\
\text { be installed on an encrypted file system to prevent access to } \\
\text { and interpretation of secret information. }\end{array}$ \\
\hline $\begin{array}{c}\text { RN0003: Encrypted data traffic and access control system: } \\
\text { access control based on permission levels and information } \\
\text { traffic (client-server) in encrypted form. }\end{array}$ \\
\hline $\begin{array}{c}\text { RN0004: Register of logs for auditing: The system must } \\
\text { record all actions of data changes of the forensic analysis } \\
\text { (register, change/edit and delete). It must keep the name of } \\
\text { the person in charge of the operation, date/time and the } \\
\text { change made to allow an audit in the system. }\end{array}$ \\
\hline
\end{tabular}

\section{2 ePerícia System Interface}

The access to the system is performed through the registration screen with login and password, which performs the access validation to the application's work area. The work screen displays cadastral information of expert (name and CPF), application closure and configuration buttons. The main function of the system is the forensic management carried out 
at crime sites, allowing the inclusion of general data such as date and time, nature of the occurrence, location where it was carried out (geolocation), among others. Three examinations classes are specified: Traffic, Against Life and Crimes Against the Patrimony Crimes, being at the discretion of the expert the selection of the type.

The application has a section for managing images and other multimedia content (content gallery) and a special section for annotations. This last section enables the forensic analyst to record various information in a textual field. This text can be further analyzed by text mining tools for the identification of descriptive patterns about locations of forensic analysis and, consequently, related crimes. Fig. 5 shows an example image recorded in the multimedia content gallery.

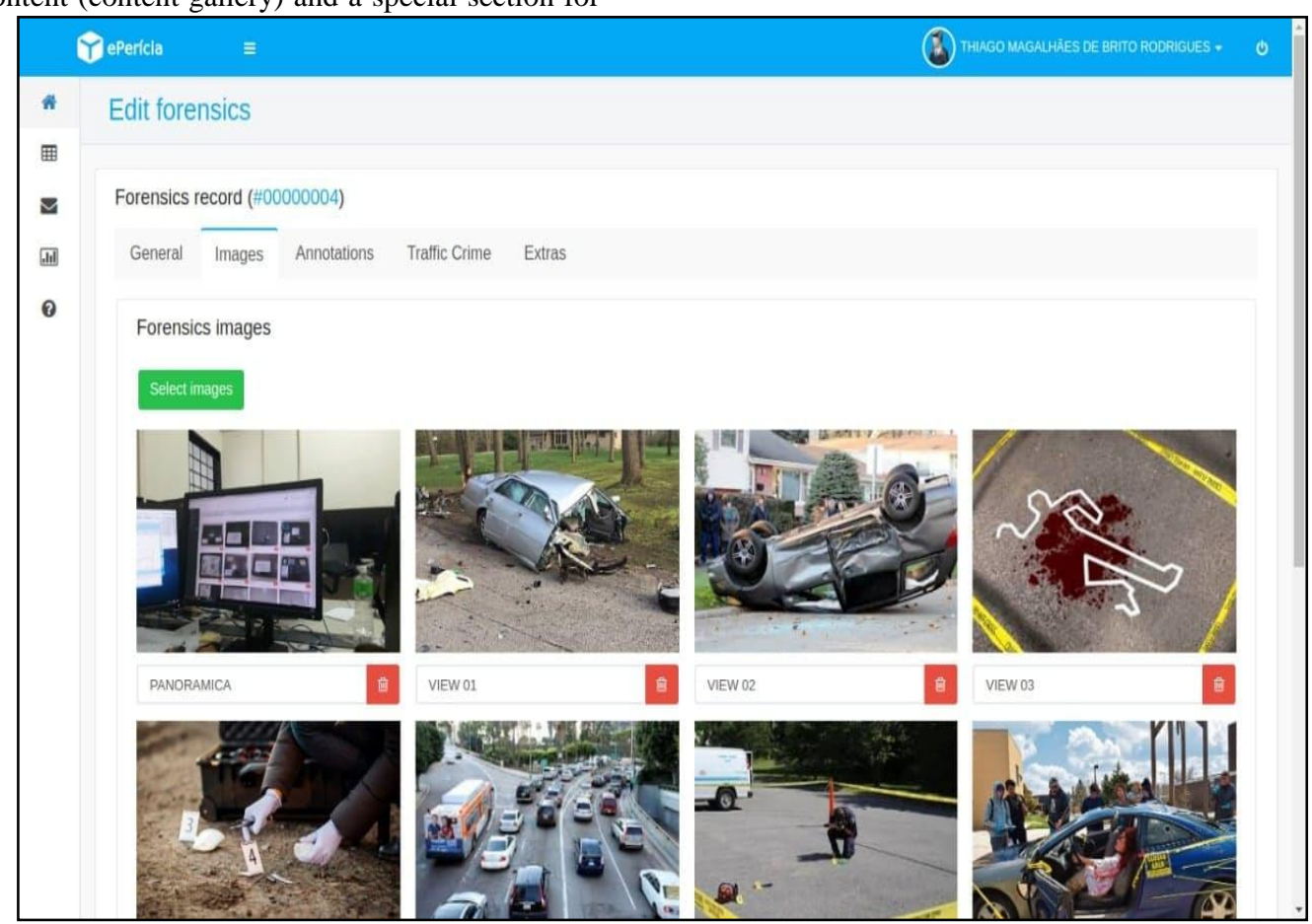

Fig 5: Image gallery management

It is important to note that it is possible to specify which security organs have insulated and preserved the local. In addition, through the geolocation API, it is possible to demarcate where the forensic analysis is being performed and present it on a map.

Once a forensic analysis is registered, it is possible to access the information through the presentation interface of the list of registered analysis. In this interface, forensic data registered by forensic analysts in system are listed. The list displays the identifier of the forensic analysis, the date and time of registration, as well as the action options of change and delete. In addition, it presents information about the type of forensic analysis (Traffic, Life, Assets or Miscellaneous).

The main interface of the application allows queries by the number of a certain forensic analysis or the occurrence date. Very important option, especially when the forensic analyst has a high number of analysis registered and linked to your login. To edit an analysis, that is, change any of your fields, just click on the "edit" icon, next to the forensic analysis that he wants to make the change. The action result is the presentation of the data of forensic analysis selected in the editing screen. To exclude a forensic analysis, the analyst must click on the exclusion icon, that, after confirmed the operation to delete the forensic analysis permanently, the system performs the exclusion of the data.

Fig. 6 shows the registration form for a new forensic analysis. A forensic analyst registered in the system, in this example, the Thiago Magalhães de Brito, has access to fill in the general data, image records, various annotations and extra information, if necessary. In addition, the system maintains a messaging management system that can be sent between forensic analysts and the institution.

In Fig. 5, the forensic analyst Thiago Magalhães is logged in the ePericia. The application maintains a menu on the left side with several options, among them the statistical visualization on the forensic reports recorded by the forensic analyst and the institution. Fig. 6 presents an example of a report made available, with the statistics of the percentage of forensic reports by nature (Traffic, Patrimony and Life) and the Fig. 7 presents an example of geolocalization crime record. 


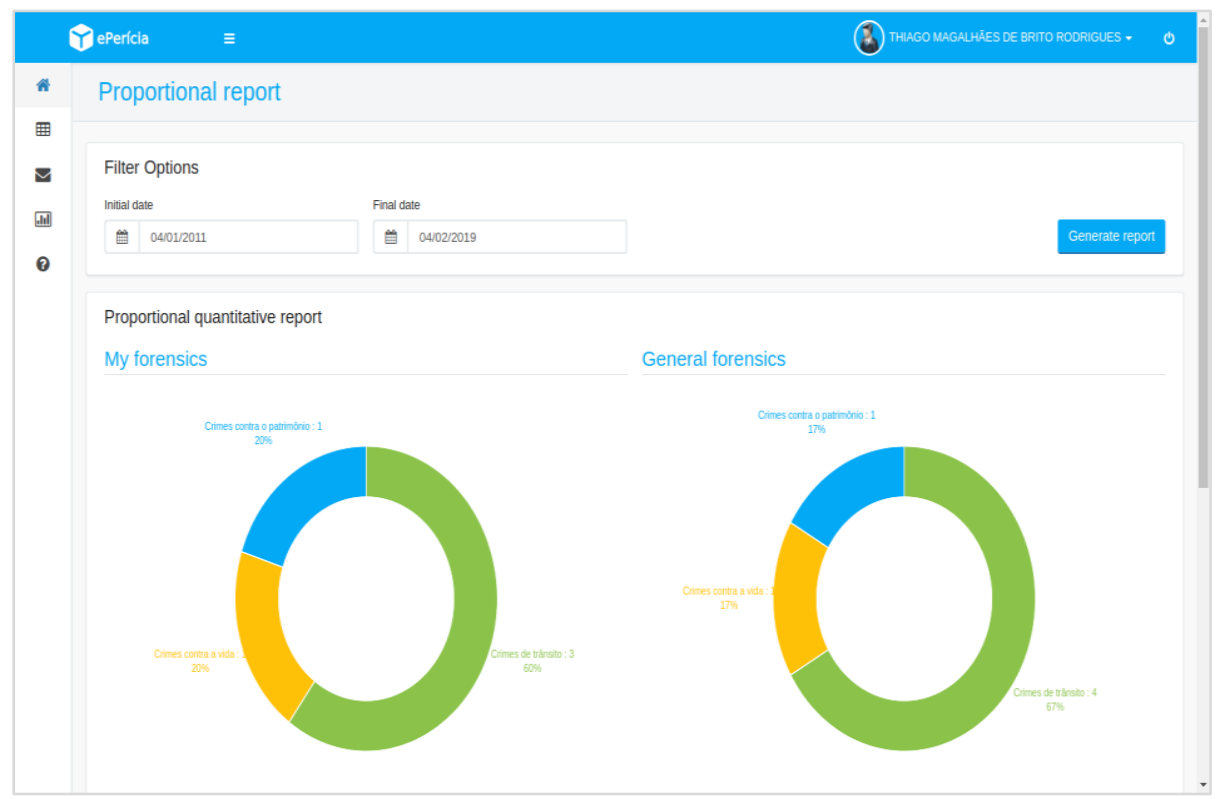

Fig 6: Registration of new forensic analysis, statistical report with percentage of forensic analysis.

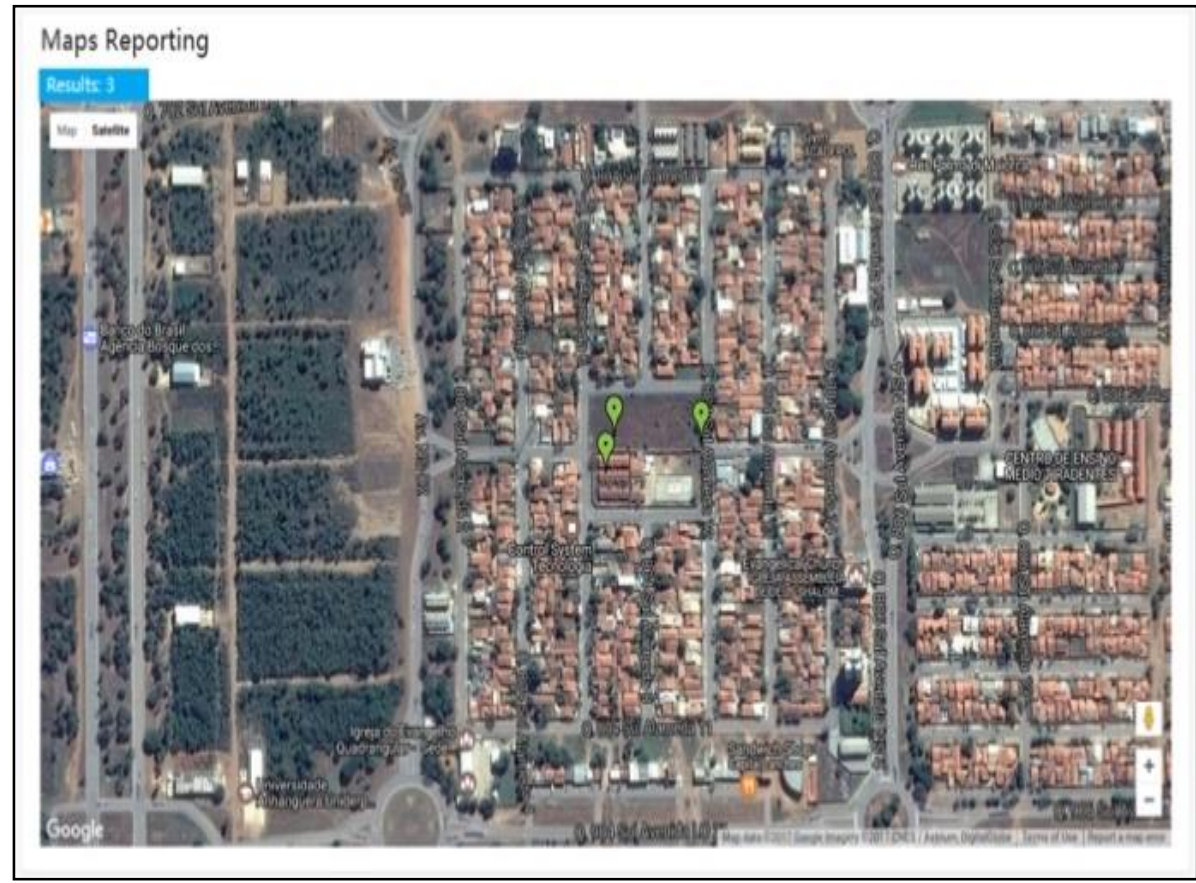

Fig 7: Registration of new forensic analysis, statistical report with percentage of forensic analysis carried out by nature and geolocation of the crime scene

Fig. 8 shows one of the interfaces used for vehicle collision recording. It enables the registration of important traffic crime information, generally encompassing the functional requirements RF0007 through RF0015 presented in Table 1. The interface of the example presents a sketch of the main types of collisions between two vehicles. Each of the schemes represents a registration option of collision type (front, semifront and etc.). These schemes are associated with a code that, once registered in the database, allows the generation of statistics and analysis of data on collision profiles, such as the percentage of each collision type, location/region, time, date, among others. It is necessary to highlight the accuracy of accident location information by geolocation using the Google API to retrieve and record latitude and longitude data.
It is important to note that due to the integration of the data collected at the investigation local and the general database of the Criminalist Institute, forensic information can be presented in the statistics of the institution in real time, allowing the institution to create a situation room for monitoring of the forensic analysis carried out online. In this way, manual work in paper is dispensed and the institution gains agility in monitoring its activities.

The information can also be shared with other institutions, in initiatives such as traffic mobile justice, implemented in the Palmas-TO city. This initiative can arbitrate on small collisions that do not involve victims at the local of the traffic accident, subsidized with the forensic data obtained and registered through ePerícia. The system can help justice to 
contribute even more effectively to reducing the waiting time for the resolution of traffic issues.

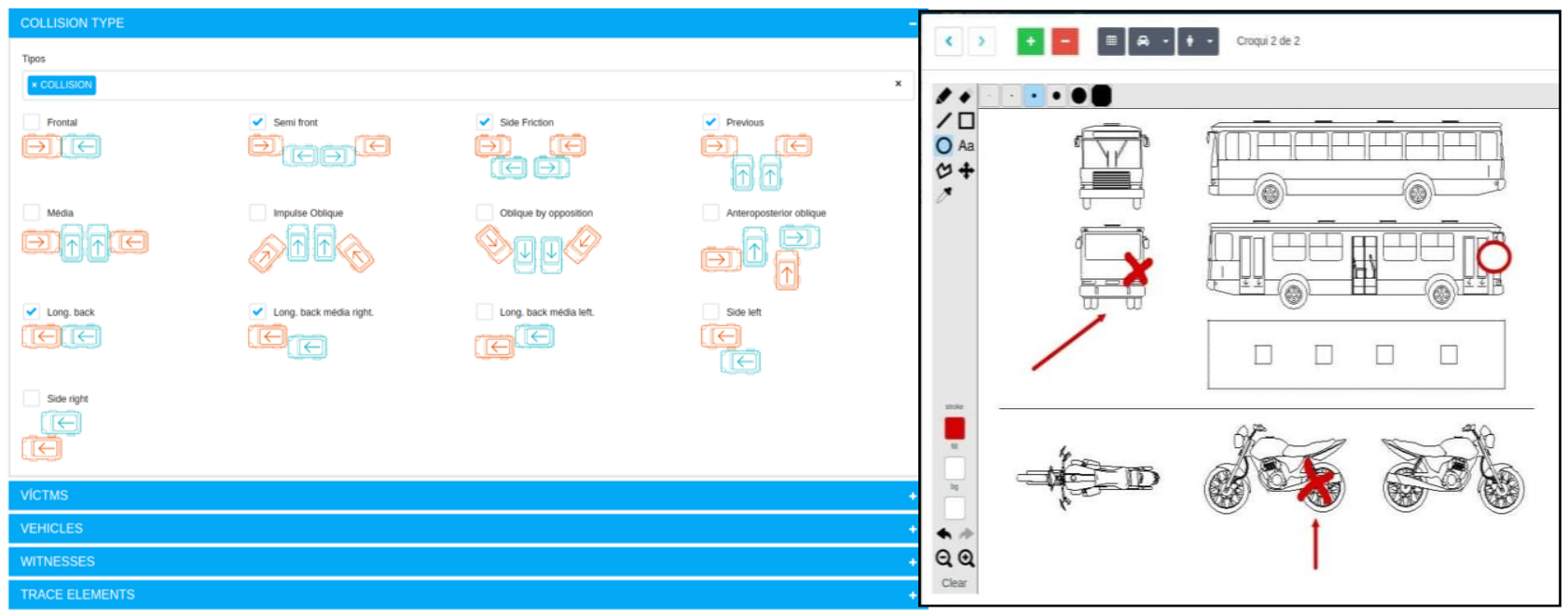

Fig 8: Interface for assembling sketches of traffic accident.

Fig. 9 shows the sketch used to record injuries in crimes against life. The application provides a predefined schema of the human body in anatomical position so that the forensic analyst can perform the filling of the information observed directly on the mobile device still in the field at the crime scene. It is possible to include several other schemes that the analyst can effectively use it in the field. The forensic analyst can also use the "hands-free" tool to draw schemas.

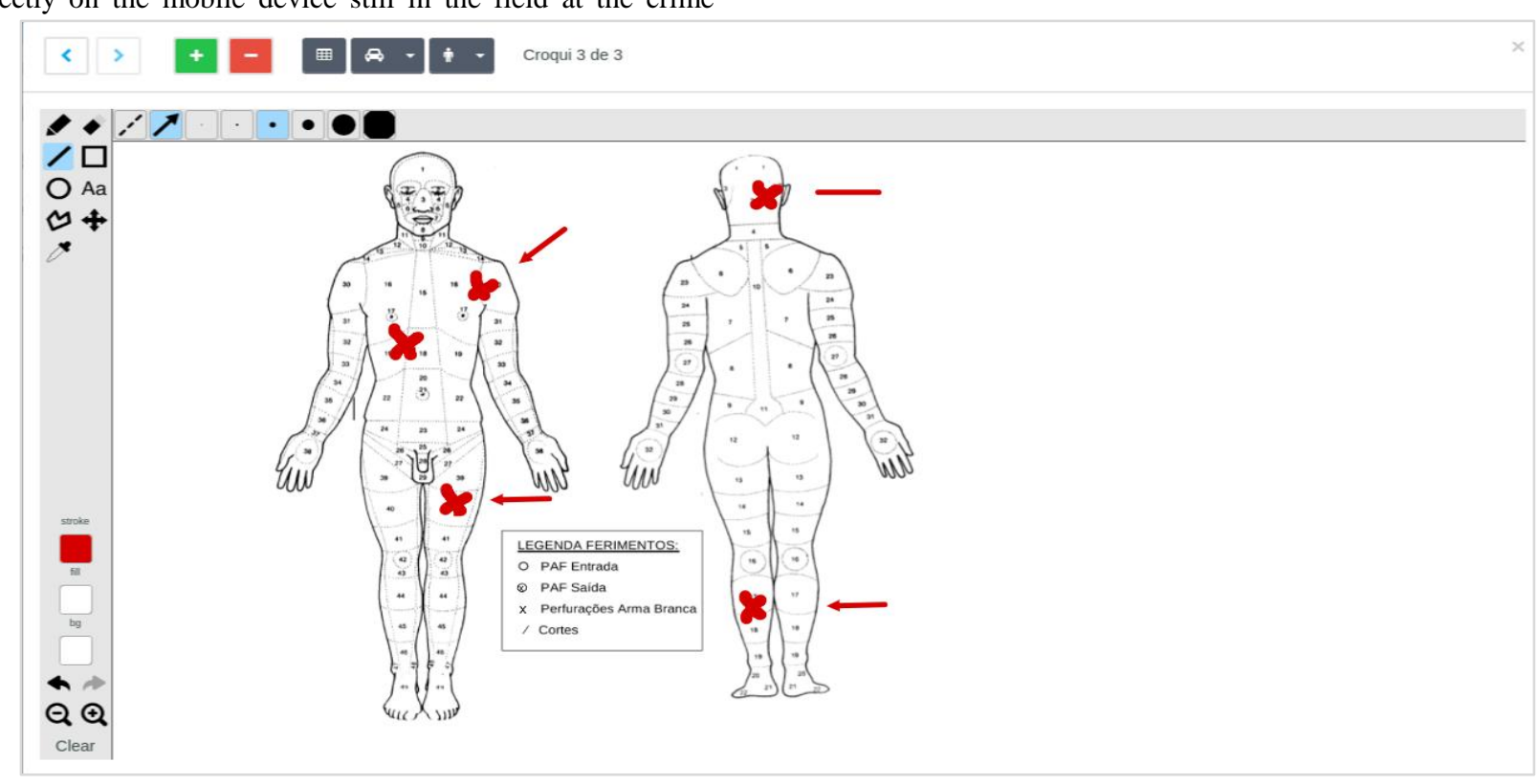

Fig 9: Interface to assemble sketches of crimes against life

The ePerícia toolkit is currently being implemented at the Forensic Analysis Unit of Porto Nacional-TO. It is a city that, according to the Brazilian Institute of Geography and Statistics, has around 52,828 inhabitants, with density of $11.04 \mathrm{hab} / \mathrm{Km}^{2}$ and an area of $4,449.91 \mathrm{Km}^{2}$.

\subsection{Evaluations and Tests}

It was proposed to execution a set of registration, updating and exclusion tasks of various forensic analysis (traffic, crimes against property, crimes against life) for the evaluation of usability by the forensic analysts. The tasks and usability questionnaires were distributed to 5 forensic analysts from the Criminalistics Institute, who represent $10 \%$ of the corporation in the Palmas-TO city. Each one performed the evaluation of the system in isolation, to avoid the influence of the others. The score attributed by each analyst is shown in Fig. 10. The
Score SUS of system was 82.0 points, reaching a B score. The result ranks ePerícia as excellent.

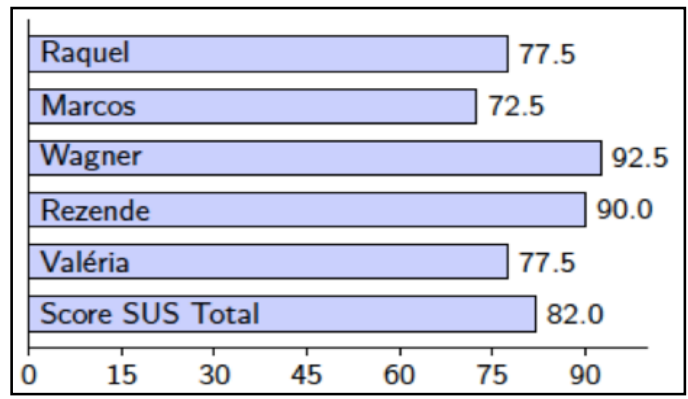

Fig 10. Results of SUS Score application 
The unit and integration tests were performed using the unit test standard library of the Django framework. All model classes, associated with database tables, passed successfully through the designed tests. As described in the methodology, the unit tests were written before the classes and their methods, which were implemented, executed and tested later. All test cases used the setUp method, which runs before each test within the test classes. This method is called to prepare the environment for running the test cases. The setUp method is called before the methods to be tested in each class and any exception generated by this method will be considered an error rather than a test failure.

The integration tests were performed in the middleware that communicates and integrates mobile and web systems. This communication allows the ePerícia web application contained in the application server to receive the data stored locally on the mobile devices. The middleware synchronizes the data and therefore should avoid duplicate records and ensure the persistence of data collected on the field via the mobile application. All data integrity assurance tests resulting from system integration returned positive error-free results.

ePerícia underwent performance testing to measure the traffic volume and workload supported by the system. 600 samples were executed that simulated 600 users simultaneously making requests. This context was created through the tool Jmeter that generated the performance graphs presenting the behavior of attendance to requests of connections and data to the system. The responses to the requests demanded an average of 7.040 milliseconds ( 7 seconds), considered an excellent result because the Tocantins State does not have 600 forensic analysts. In addition, ePerícia can handle 2,202 requisitions per minute, representing an excellent flow rate. The flow rate is characterized as the most important attribute of the performance analysis, since it represents the load capacity to serve the requests supported by the system.

\section{CONCLUSIONS}

The developed system, ePerícia, allows to store the forensic data of the Criminalistics Institute of the Tocantins State to preserve the information in a safe and reliable way. The implementation of the solution ensured greater efficiency in the registration and retrieval of the forensic reports properly stored in the database of the institution. The project was developed after the selection of innovation projects developed and/or under development to reduce homicides and promote public safety, reinforcing the potential of the proposed solution. e-Perícia system is undergoing constant updates to the insertion of new requirements, through the agile Scrum development model, in order to improve the functionalities.

The unit and integration tests allowed the verification of the program execution logic and guaranteed the construction of code free of operational errors. The tests ensure that the component works according to the characteristics and constraints defined in the system design. The results of the usability research, using the SUS method, proved that ePerícia meets the requirements and expectations of the institution, since the metrics obtained reflect a usability evaluated positively by the users.

The system can be improved to generate a greater variety of statistical analyzes or standards, for example, detailing the characteristics and pattern of the forensic analysis in relation to the occurrences nature (crimes against property, crimes against life, traffic accidents). In addition, it is necessary to treat the access of information by third parties. The judiciary would be an example of an external institution that could benefit from the exchange of information to bring together forensic reports to the electronic process systems of the institution through middleware, consumed for example by the e-proc system [20]. Currently, system information is only available to the Criminalistic Institute technical staff who can generate reports in digital or physical formats. The ePerícia System was registered with the Brazilian Institute of Industrial Property under number BR512018052490-7.

\section{ACKNOWLEDGMENTS}

We thank the Brazilians research funding agencies FINEP and Research Program for Brazilian Single Health System (PPSUS) for financing the equipment used in the development of this work. We are grateful to the Forensic Analysts and the Criminalistics Institute of the Tocantins for the willingness to contribute essential information and the body of experts for the development of the system. We also thank to the Federal University of Tocantins, especially the Computer Science Course, for providing the human and technological resources essential for the implementation and deployment of ePerícia.

\section{REFERENCES}

[1] Almeida, R. V. 2013. A Função Essencial da Justiça e a Função social da perícia [The Essential Justice Function and the Criminal Investigation Social Function]. Ambito Jurídico, 114

[2] Beck, K 2002. Test-Driven Development by Example. Addison-Wesley Professional.

[3] Bhat, T., Nagappan, N., Maximilien, E. M.; Williams, L. 2008. Realizing quality improvement through test driven development: results and experiences of four industrial teams. Springer Empirical Software Engineering,13.

[4] Brooke, J. K. 1996. SUS: A quick and dirty usability scale. Taylor and Francis, United Kingdom.

[5] Brooke, J. K. 2013. SUS: A retrospective. JUS Journal of Usability Studies, 8, 29-40.

[6] Castro, J. B., Carvalho, A. E. S. \& Tavares, H. C 2001. Uma estratégia para implantação de uma gerência de requisitos visando a melhoria dos processos de software [A strategy for implementing of requirements management for software processes improvement]. Federal University of Pernambuco.

[7] Constituição da República Federativa do Brasil de 1988. 2001. Coleção Saraiva de Legislação. (21a ed.). São Paulo: Saraiva.

[8] Decreto Lei $\mathrm{n}^{0} 3.689$ de 03 de outubro de 1941. Código de Processo Penal. Presidência da República. Retrieved from: http://www.planalto.gov.br/ccivil_03/decretolei/Del3689.htm

[9] Guerra, E.; Aniche, M. 2015. Achieving quality on software design through test-driven development. In: Mistrik, I., Soley, R., Ali, N., Grundy, J.; Tekinerdogan, B. (Eds.). Software Quality Assurance in Large Scale and Complex Software-Intensive Systems. Morgan Kaufmann Elsevier, 201-220.

[10] Gupta; A., Tiwari, S. \& Rathore, S. S. (2012). Selecting requirement elicitation techniques for software projects. 2012 CSI Sixth International Conference on Software Engineering (CONSEG) 1-10.

[11] Institute of Electrical and Electronics Engineers (IEEE). 1990. Standard Glossary of Software Engineering Terminology. IEEE Computer Society. 
[12] Kehdy, C. 1959. Manual de locais de crime. Escola de Polícia. São Paulo, $3^{\mathrm{a}}$ ed.

[13] Kirk, P. 2010.Conscientização sobre o local de crime e as evidências materiais em especial para pessoal nãoforense. Laboratório e Seção Científica. United Nations Office on Drugs and Crime, Vienna, 1a ed., 2010.

[14] Lei $n^{\circ} 12.030$ de 17 de setembro de 2009. 2009. Dispõe sobre as Perícias Oficiais. Presidência da República. Casa civil, Subchefia para Assuntos Jurídicos. Retrieved from: http://www.planalto.gov.br/ccivil_03/_ato20072010/2009/lei/l12030.htm.

[15] Lima, C. J. A. 2012. Modernização organizacional da criminalística brasileira: Uma proposta [Brazilian Criminalistics Organizational Modernization: A proposal]. [Masther's Thesis]. Fundação Getúlio Vargas.

[16] Ministério da Justiça e Segurança Pública - MJSP. 2017. Edital 01 e 02/2015: Chamada de Projetos do Laboratório de Participação e Inovação para Redução de
Homicídios [Call for Project Financing from the Participation and Innovation Laboratory to Homicide Reduction]. Processo 08004.001091/2015-67.

[17] Sauro, J. 2011. Measuring usability with the system usability scale (SUS). Usability Testing Analysis. Retrieved from https://measuringu.com/sus/

[18] Smith, C. U. 1990. Performance Engineering of Software Systems. Addison-Wesley Longman Publishing Co., Inc.

[19] Tenerowicz, C. L. 2008. Elicitation techniques. Cornell University, USA.

[20] Tribunal de Justiça do Estado do Tocantins - TJTO 2018. Poder Judiciário. Sistema e-Proc/TJTO [e-Proc Judicial Process Information System]. Retrieved from https://eproc.tjto.jus.br/

[21] Velho, J. A., Costa, K. A. e Damasceno, C. T. M. 2013. Locais de Crime: Dos Vestígios à Dinâmica Criminosa. Millennium, 1a edição. 